\title{
Prospecção Tecnológica sobre Sistemas de Geolocalização Voltados para Passageiros de Trem
}

\author{
Technological Prospection on Geolocation Systems for Train Passengers
}

\author{
Adriana Monteiro da Cunha ${ }^{1}$ \\ ${ }^{1}$ Universidade Federal do Sul e Sudeste do Pará), Marabá, PA, Brasil
}

\begin{abstract}
Resumo
A geolocalização é utilizada para rastrear um sujeito ou objeto a partir de sua coordenada geográfica de modo automático. É empregada a partir de um conjunto de hardware, software e dados geográficos. Este estudo apresenta uma análise sobre patentes associadas à geolocalização de composições ferroviárias e a dispositivos móveis que identifiquem, em tempo real, o status de viagem das mesmas com o objetivo de avaliar as tecnologias disponíveis no Brasil e no mundo, para dar suporte a passageiros e comunidades que vivem próximas às linhas de trens. A partir dos resultados, observa-se o baixo uso da tecnologia empregada em serviços destinados a passageiros $e$ comunidades que vivem próximas à linhas de trem e de metrôs no Brasil.
\end{abstract}

Palavras-chave: Geolocalização. Dispositivo móvel. Mobilidade.

\begin{abstract}
Geolocation is used to automatically track a subject or object from its geographic coordinate. It is employed from a set of hardware, software and geographic data. This study presents an analysis of patents associated with railway composition and mobile device geolocation that identify, in real time, their travel status in order to evaluate the technologies available in Brazil and worldwide to support passengers. and communities living near the train lines. From the results, we can observe the low use of the technology used in services for passengers and communities that live close to the train and subway lines in Brazil.
\end{abstract}

Keywords: Geolocation. Mobile device. Mobility.

Área Tecnológica: Propriedade Industrial. Transporte Ferroviário e Metroferroviário. Mobilidade Urbana.

\section{Introdução}

O transporte ferroviário voltou à pauta dos governos brasileiros nos últimos cinco anos, em nível federal e estadual, culminando com a renovação das concessões de atuais linhas férreas e de novas concessões planejadas pela Agência Nacional de Transportes Terrestres (ANTF) em propostas para o setor prevendo o triênio 2019-2022 (ANTF, 2018). Por ser uma opção mais econômica e com maior eficiência energética para a logística de cargas e segura para os passageiros, se comparada às rodovias, esta opção entrou no debate para novas concessões de linhas junto ao setor privado em todo o Brasil, retomando as discussões acerca do modal 
de transportes adotado no país e seus efeitos no escoamento da produção e na mobilidade urbana (ANTT, 2014).

Com o objetivo de realizar um diagnóstico da malha ferroviária existente no Brasil, a Agência Nacional de Transportes Terrestres (ANTT) realizou um levantamento que aponta a subutilização de vias férreas no país. O levantamento mostra, ainda, que estas vias podem ser recuperadas e destinadas ao transporte de pessoas e de cargas, sendo uma das soluções para a mobilidade nos grandes centros urbanos e para a diversificação do modal logístico, que ainda conta com as mesmas estruturas de 50 anos atrás (ANTT, 2014). Entre os modais de transporte disponíveis em território brasileiro estão o ferroviário, o rodoviário, o hidroviário, o dutoviário e o aeroviário.

Em São Paulo, cidade com a maior malha ferroviária e metroferroviária do país, o objetivo é não só abrir novas concessões como privatizar os atuais sistemas metroferroviários compostos pelo Metrô de São Paulo (Companhia do Metropolitano de São Paulo) e pela CPTM (Companhia Paulista de Trens Metropolitano), com o objetivo de conservar a estrutura, modernizar os serviços e implementar novos pátios de cruzamento (DIÁRIO DO METRÔ, 2019). Por outro lado, tramita na Assembleia Legislativa do Estado de São Paulo um projeto de lei que regulamenta a concessão de linhas do Metrô de São Paulo (Companhia do Metropolitano de São Paulo) e da CPTM (Companhia Paulista de Trens Metropolitano) à iniciativa privada (DIÁRIO DO METRÔ, 2019).

Quanto aos trens ferroviários, as duas linhas de transporte de passageiros existentes no país, ambas operadas pela Vale S. A., disponibilizam seus serviços apenas no site oficial da empresa, sem operar com sistema responsivo (que adaptam o tamanho das suas páginas - layout - ao tamanho das telas em que estão sendo exibidos) para aparelhos mobile (celulares e tablets) (www.vale.com).

Estudo feito pela Confederação Nacional de Transportes (2018) aponta que existe uma demanda por expansão exigida pela população dos aglomerados urbanos onde operam trens metroferroviários, sobretudo pela confiabilidade operacional deste transporte. No Brasil, a maior concentração de metrôs está na região Sudeste, com destaques para os estados de São Paulo, Rio de Janeiro, Minas Gerais e na região Sul, no Rio Grande do Sul, além das malhas existentes nas cidades de Fortaleza, Salvador, Recife, Natal, Maceió, João Pessoa, Sobral (CE), Teresina e do Distrito Federal.

Além disto, há uma intencionalidade da sociedade civil e de organismos ligados a questões ambientais, no Brasil e no mundo, de priorizar o transporte coletivo em relação ao transporte individual, em virtude de questões ambientais (emissão de gases do efeito estufa pelos veículos automotores) (TATTO, 2015).

Por outro lado, a sociedade ainda conta com poucos serviços de utilidade pública ou tecnologias que deem suporte à interface destes passageiros e superficiários ${ }^{1} \mathrm{com}$ os trens urbanos e ferroviários ao longo das suas respectivas malhas.

Conforme cita o site da Embaixada do Japão no Brasil (2019), no mundo, os países de origem oriental são os que mais investem em pesquisa e desenvolvimento de patentes relacionadas ao transporte ferroviário, seja por segurança operacional seja para serviços voltados aos usuários, tendo as universidades como seus principais vetores de estudos relacionados ao tema.

${ }^{1}$ Superficiário: proprietário ou morador de terreno próximo à linha do trem. 
Este estudo apresenta uma prospecção sobre patentes associadas à geolocalização de composições ferroviárias por meio de dispositivos móveis/aplicativos que facilitem o acesso de informações, em tempo real, sobre os horários de chegada e partida das composições em estações e pontos de parada.

O objetivo é avaliar as tecnologias disponíveis no Brasil e no mundo para dar suporte a passageiros e superficiários de trens, melhorando suas relações com as operações deste modal, seja para serviços de utilidade pública seja para ter maior segurança na travessia das linhas ao longo do trecho ferroviário.

O estudo teve como objetivo identificar patentes ou o uso de dispositivos móveis e/ou aplicativos que permitam identificar a localização de trens em tempo real, como serviço disponibilizado pelas operadoras ou concessionárias de trem voltado aos usuários deste transporte.

\section{Metodologia}

A metodologia adotada neste estudo foi composta por revisão bibliográfica e documental, coleta de dados junto aos principais operadores de transporte ferroviário e metroferroviário no Brasil, levantamento de informações em sites e portais de notícias, além de busca de patentes no Instituto Nacional da Propriedade Industrial (INPI) e no Escritório Europeu de Patentes (Espacenet $\left.{ }^{\circledR}\right)$, plataformas online adotadas para a realização deste trabalho.

Na pesquisa avançada realizada nas plataformas do INPI e Espacenet, foram utilizadas as seguintes palavras-chave: trem (train), geolocalização (geolocation) e dispositivo móvel (mobile device), identificadas a partir do escopo do trabalho. Estas palavras foram inseridas nos campos 'título' e 'resumo' de cada uma das plataformas acima mencionadas.

Após o primeiro levantamento de registros, foi identificado o código internacional de patentes (IPC) G01S19/50, que também foi usado na pesquisa. O código trata dos sistemas de posicionamento de radiofarol por satélite determinando posição, velocidade ou atitude usando sinais transmitidos por tais sistemas e transmitindo mensagens com marcação de tempo (time-stamped), por exemplo GPS, informando ao passageiro o status do local e do horário exatos da viagem.

Em busca de filtrar os resultados, foi utilizado o operador booleano AND e o operador de truncagem (*) na busca avançada associados às palavras-chave ora mencionadas, tanto no título quanto no resumo. Além disto, a pesquisa também combinou o código IPC G01S19/50 às palavras-chave. O resultado extraído das buscas foi distribuído e elaborado a partir de gráficos demonstrativos, que evidenciaram o cenário tecnológico e desenvolvimento de tecnologias na área de estudo proposta.

A Tabela 1 apresenta o escopo da busca, por meio da qual foi identificado um número considerável de registros de patentes a partir da palavra-chave "geolocation*" (1.203) e do código G01S19/50 (1.072), com maior volume no Espacenet. A maioria destes registros diz respeito à localização de trens com o objetivo de monitoramento operacional e de segurança da tripulação, tendo pouca relação com o escopo da pesquisa proposta. 
Tabela 1 - Escopo de busca

\begin{tabular}{|c|c|c|c|c|c|c|c|c|}
\hline \multicolumn{6}{|c|}{ Palavras-chave } & Código & \multicolumn{2}{|c|}{ EsCRITÓRIOS } \\
\hline Geolocation* & Geolocalização & Train* & Trem & $\begin{array}{c}\text { MobiLe } \\
\text { DEVICE }\end{array}$ & $\begin{array}{c}\text { DisPositivo } \\
\text { MÓVEL }\end{array}$ & G01S19/50 & INPI & ESPACENET \\
\hline \multirow[t]{2}{*}{$X$} & & & & & & & - & 1.203 \\
\hline & $\mathrm{X}$ & & & & & & 24 & - \\
\hline \multirow[t]{2}{*}{$\mathrm{X}$} & & $\mathrm{X}$ & & & & & - & 1 \\
\hline & $\mathrm{X}$ & & $\mathrm{X}$ & & & & 0 & - \\
\hline \multirow[t]{9}{*}{$\mathrm{X}$} & & $X$ & & $\mathrm{X}$ & & & - & 0 \\
\hline & $\mathrm{X}$ & & $\mathrm{X}$ & & $\mathrm{X}$ & & 0 & - \\
\hline & & & & & & $X$ & 2 & 1.070 \\
\hline & & $\mathrm{X}$ & & $X$ & & $\mathrm{X}$ & - & 2 \\
\hline & & & $X$ & & $X$ & $X$ & 1 & - \\
\hline & & $\mathrm{X}$ & & $\mathrm{X}$ & & $\mathrm{X}$ & 0 & 2 \\
\hline & & & $X$ & & $X$ & $\mathrm{X}$ & 0 & - \\
\hline & & $\mathrm{X}$ & & & & $\mathrm{X}$ & - & 35 \\
\hline & & & $X$ & & & X & 1 & - \\
\hline
\end{tabular}

Fonte: Elaborada pela autora deste artigo (2019)

\section{Resultados e Discussão}

Utilizando-se a combinação da palavra-chave "train" com o código IPC G01S19/50 foram detectadas 35 patentes na busca realizada no Espacenet ${ }^{\circledR}$ e uma no INPI. Todas foram avaliadas de maneira individual, por meio dos seus respectivos resumos. Após a seleção, foram excluídas as patentes que não estavam diretamente relacionadas ao tema da pesquisa.

Foi encontrada uma patente relacionada diretamente com o objeto deste estudo e seu registro é de origem japonesa, mais precisamente depositada pela empresa Casio Computer Co LTD, em 2010. Trata sobre sistema para detectar o local atual da rota do trem, bem como em qual estação ele se encontra, oferecendo ao usuário a possibilidade de acompanhar a distância da composição entre as estações e os pontos de parada, além de calcular a distância entre a estação de partida e a estação de chegada.

$\mathrm{Na}$ base do INPI foi identificada uma única patente, que, embora não tenha relação direta com o objeto deste trabalho, foi considerada para fins de avaliação das tecnologias adotadas no país para geolocalização de trens. Se comparada a outros países, a China está à frente no número de depósitos de patentes relacionadas a sistemas de geolocalização de trens, conforme demonstrado na Figura 1. No total, foram identificadas 14 patentes chinesas registradas na base do Espacenet. 
Figura 1 - Patentes por países

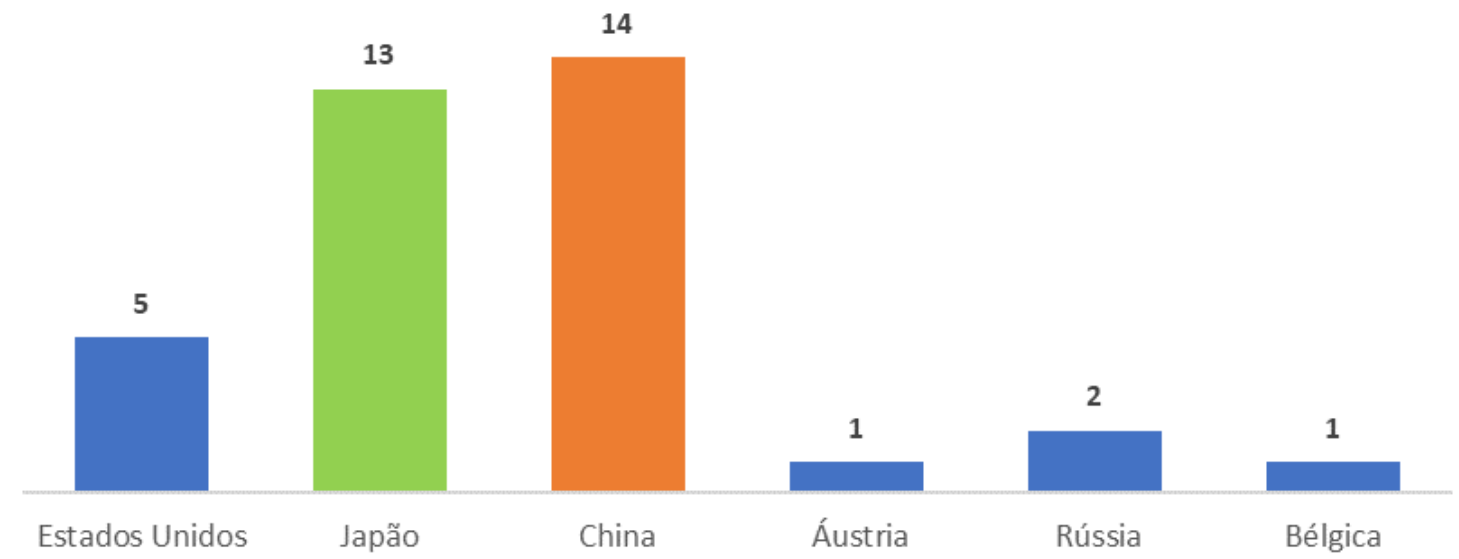

Fonte: Elaborada pela autora deste artigo (2019)

A malha de trens na China está presente em mais de 500 cidades do país e chega a uma extensão total de 127 mil quilômetros. Possui o trem bala mais rápido do mundo, o qual alcança uma velocidade de $350 \mathrm{~km} / \mathrm{h}$. Além disto, é importante ressaltar que a tecnologia, neste exemplo, está a serviço do usuário: pontualidade, comodidade e qualidade são alguns dos benefícios usufruídos pelos passageiros. O Japão, que também conta com um sistema de trens e metrôs de elevado padrão e um dos mais avançados do mundo, aparece em segundo lugar na pesquisa realizada, ratificando a liderança dos países orientais na produção e registros de patentes alusivas ao tema deste estudo (CARTA MAIOR, 2018).

Por outro lado, as ferrovias existentes no Brasil têm maior foco no transporte de cargas em geral e de minérios. Os trens urbanos estão concentrados, em maior escala, nas regiões Sudeste e Sul. A mineradora Vale opera dois trens de passageiros no Brasil, sendo um na Estrada de Ferro Carajás (EFC), que cruza 27 localidades entre os estados do Pará e do Maranhão; e outro na Estrada de Ferro Vitória a Minas (EFVM), passando por 30 pontos de embarque e desembarque entre os estados de Minas Gerais e Espírito Santo. Estes são os dois únicos trens ferroviários com transporte contínuo de passageiros existentes, hoje, no país: são cerca de 3.000 usuários por dia na EFVM e outros 1.800 na EFC (www.vale.com).

A única patente relacionada à geolocalização de trens registrada no Brasil é de origem norte-americana, da empresa Via Rail Canada INC, e diz respeito a um método para auxiliar na operação segura de trens, com controle do trem por uma tripulação a partir de GPS. O objetivo é monitorar a localização do trem em tempo real e identificar situações que possam ser contingenciadas de maneira remota (Registro: BR 1020150084986 A2).

Conforme a Figura 2, observa-se que o campo de pesquisas com a temática de serviços voltados para os passageiros por meio de sistema de geolocalização de trens no Brasil ainda é pouco explorado, indicando um nicho com boas perspectivas para a inovação, considerando-se novos mercados e a relevância da tecnologia para a mobilidade de pessoas. 
Figura 2 - Bases de dados adotadas na pesquisa

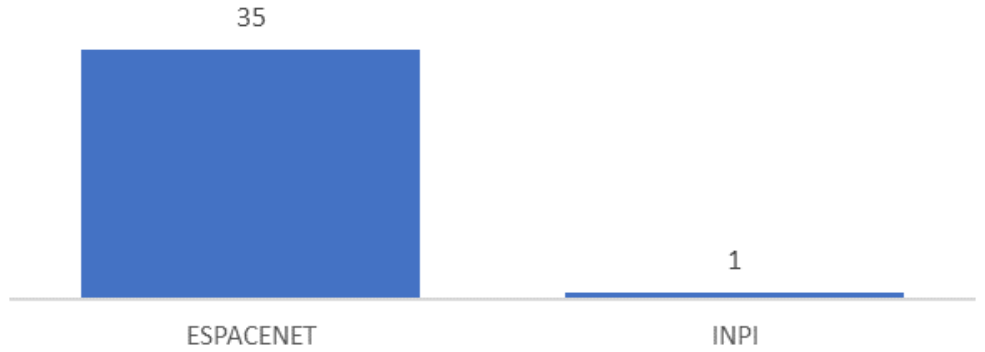

Fonte: Elaborada pela autora deste artigo (2019)

No Brasil, o metrô urbano de São Paulo é o único a contar com aplicativos (Metrô de São Paulo Oficial e Moovit) que oferecem, entre outras funcionalidades, serviço que permite ao passageiro acompanhar em tempo real o status de cada uma das linhas, além de simular o caminho mais rápido entre duas estações, tempo, custos e mapas. Especificamente para estes serviços, não foram identificados registros de patentes na base do INPI durante esta pesquisa. Os aplicativos também trazem informações sobre horário de funcionamento, valor de tarifas, telefones úteis e sobre todas as linhas e estações disponíveis na malha metropolitana paulista. Nas avaliações dos usuários dispostas na Play Store (sistema Android), os dispositivos são avaliados com bastante comentários negativos sobre mau funcionamento, falhas contínuas $e$ informações desatualizadas.

Vocês poderiam colocar a atualização de rotas e horários em segundo plano, pois não podemos ficar muito tempo com o celular na mão por causa da segurança. Poderiam também colocar informações sobre acidentes, obras e demora no tráfego, pois muitas vezes essas situações também atrapalham os horários em até cinco minutos. (RIBEIRO, Tiago, 2019 - Usuário do aplicativo Moovit em comentário na Play Store).

O APP tem um mínimo de utilidade, não tem nada em tempo real, desconhece a totalidade das rotas, conexões, etc... E tem mais: não entendo o motivo de a única maneira de reclamar é via SMS e não pelo próprio aplicativo (opcionalmente), onde se poderia tirar fotos do denunciado, da identificação do carro do metrô, sentido, etc. (RDM, Luiz, 2019 - Usuário do aplicativo Metrô de São Paulo, em comentário na Play Store).

O mercado mobile é dinâmico e é de suma importância que os desenvolvedores de aplicativos acompanhem as mudanças ocorridas nos sistemas operacionais dos smartphones, com o objetivo não só de melhorar a qualidade do produto oferecido aos usuários, bem como evitar prejuízos à reputação da empresa ligada àquele serviço (MARTIN, 2013). A falta de atualizações constantes nestes dispositivos gera a percepção, junto à sociedade, de que a empresa não preza pelos serviços direcionados ao seu público consumidor, como também a de que não acompanha as novas tecnologias existentes no mercado (MARTIN, 2013).

Quanto à origem das patentes pesquisadas, a Figura 3 demonstra que os registros, em sua maioria, são originários de empresas privadas, seguidas pelas universidades chinesas. As instituições de ensino superior na China são destaque no mundo em qualidade de ensino e ocupam duas entre as quinze primeiras posições do ranking da revista Times Higher Education (THE) em 2019 (www.timeshighereducation.com). O estudo traz um levantamento com as universidades de maior prestígio em nível mundial. A Universidade de Pequim Jiaotong - que tem o maior 
o número de registros de patentes do tema relacionado a este trabalho (Figura 3) - é uma das instituições que se destaca em ciência e tecnologia para transporte no mundo.

Figura 3 - Registros de patentes por empresas

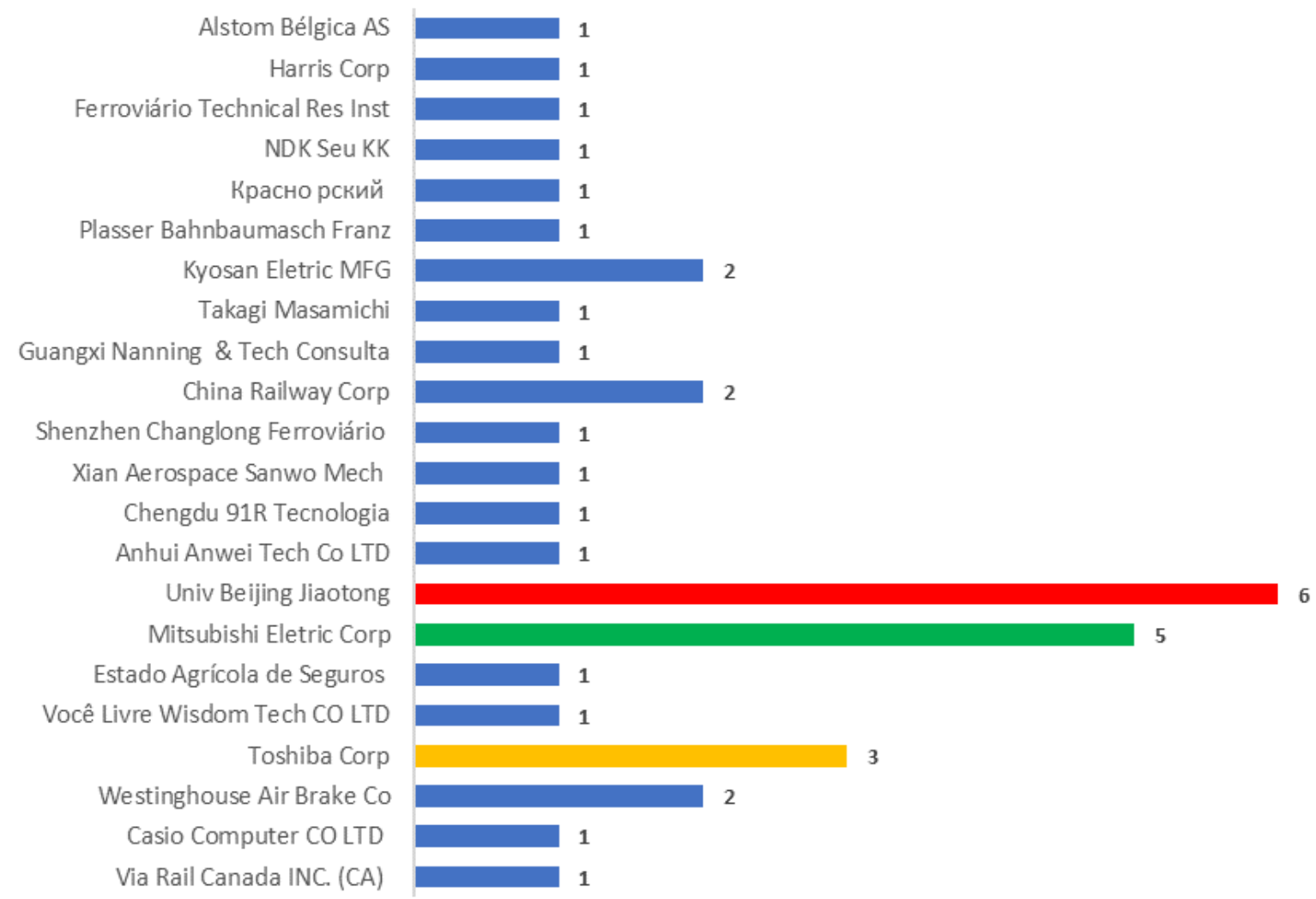

Fonte: Elaborada pela autora deste artigo (2019)

Embora os primeiros registros de patentes relacionadas à geolocalização de trens apareçam entre os anos de 1998 e 1999 na base do Espacenet, sendo ambas depositadas por empresas dos Estados Unidos, observa-se que o tema vem sendo explorado em maior escala nos últimos cinco anos. Foram 11 registros somente em 2018, e nos sete primeiros meses de 2019 foram identificadas cinco patentes, conforme está ilustrado na Figura 4.

Figura 4 - Evolução anual das patentes pesquisadas

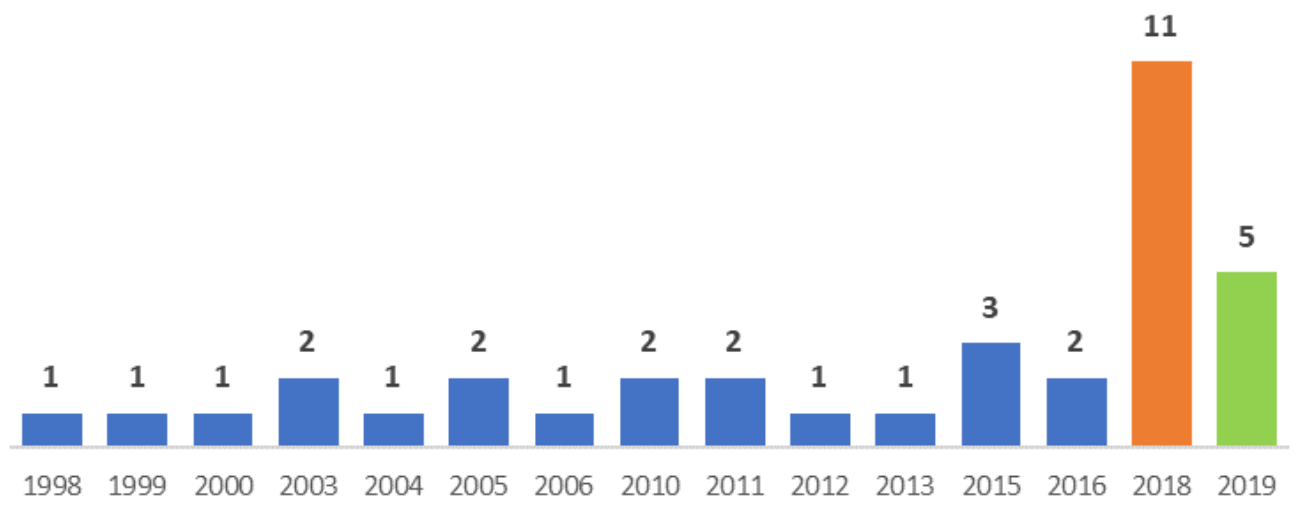

Fonte: Elaborada pela autora deste artigo (2019) 
Observa-se, ainda, que o Japão é o país com maior frequência em depósitos e registros de patentes relacionadas à geolocalização de trens se avaliado o histórico dos últimos 20 anos, conforme representado na Figura 5. Os Estados Unidos aparecem em segundo lugar na evolução histórica, sendo um dos países pioneiros no registro de produtos relacionados à geolocalização, ainda na década de 1990.

Figura 5 - Evolução anual de registros de patentes por países

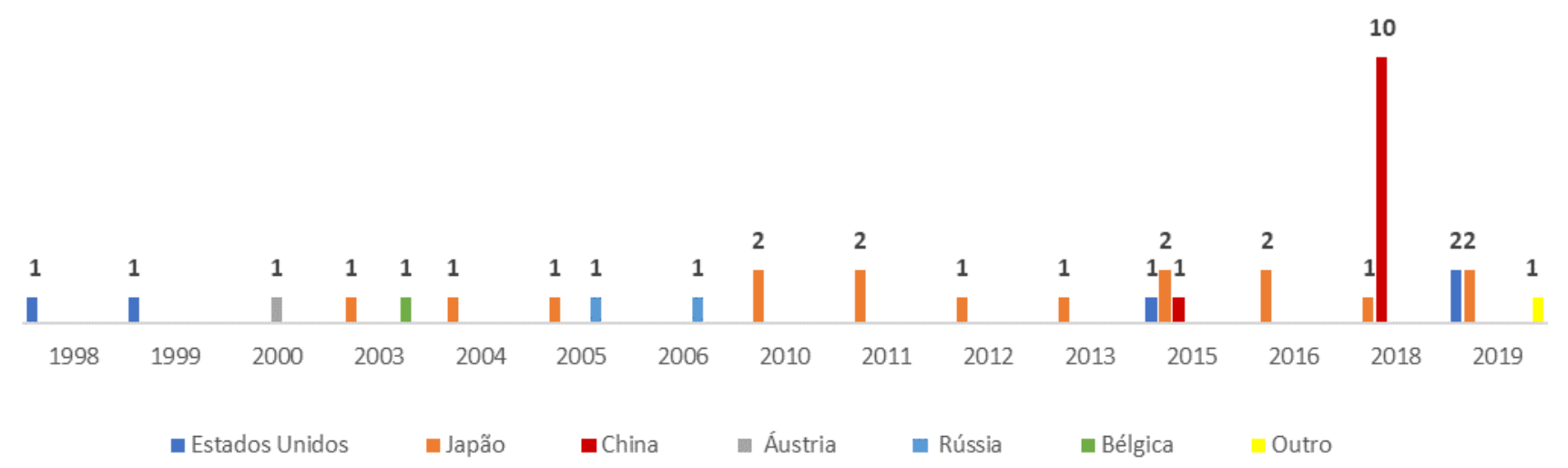

Fonte: Elaborada pela autora deste artigo (2019)

A malha ferroviária norte-americana é a mais extensa do mundo, com cobertura total de uma área de 226,612 mil quilômetros de vias férreas (Figura 6). O transporte ferroviário nos EUA é controlado pelo Governo, que subsidia e supervisiona os serviços de transporte de passageiros no país, com mais de 500 destinos e está presente em 46 estados. A média diária de passageiros é de 82 mil pessoas (www.amtrak.com). A companhia AMTRACK, operadora de trens nos Estados Unidos, disponibiliza aplicativo tanto para sistemas operacionais IPhone como para Android, com informações sobre viagens, status do trem e compra de passagens online, entre outros serviços.

Figura 6 - Cobertura das malhas ferroviárias de Brasil, China, Estados Unidos e Rússia

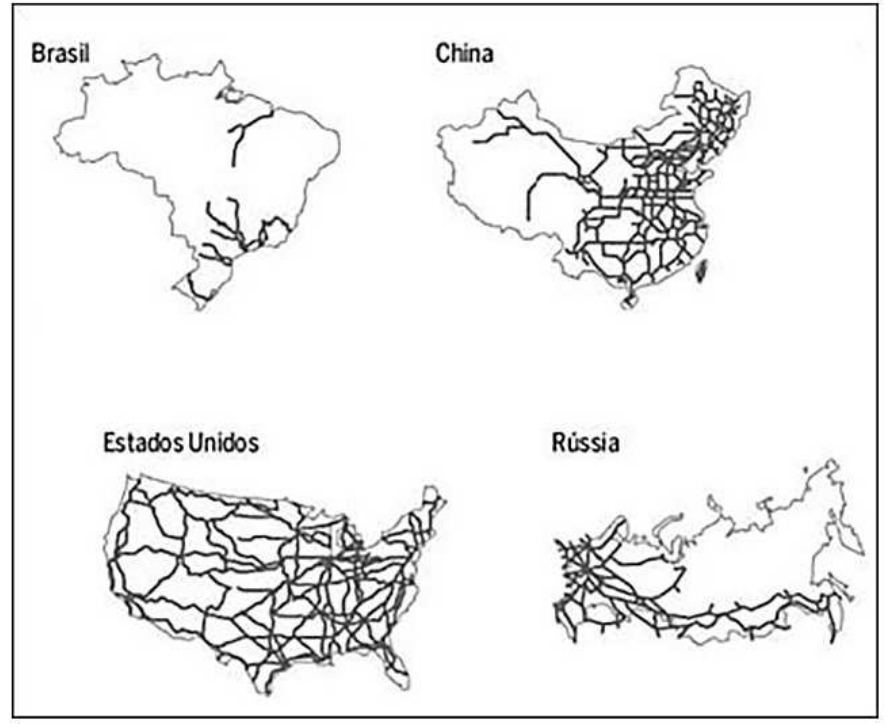

Fonte: Reprodução site Forte Forças Terrestres (www.forte.jor.br). 
Na China, o transporte ferroviário está ligado, diretamente, à expansão econômica do país. São mais de 127 mil quilômetros de linhas férreas. Somente em 2017, foram realizadas mais de 3,04 bilhões de viagens de passageiros, sendo que $56 \%$ deste transporte foram realizados em ferrovias de alta velocidade, de acordo com notícia veiculada no portal da Carta Maior. Mais de $70 \%$ dos serviços voltados para passageiros e, ainda, para negócios de cargas em território chinês é realizado de forma online.

No Japão, o sistema ferroviário é operado por companhias privadas e conta com aproximadamente 27,796 quilômetros de linhas, com foco em transporte de longa distância. Em 2012, a Embaixada do Japão no Brasil aponta, em seu site oficial, que foram transportadas mais de 22,79 milhões de pessoas. O investimento da iniciativa privada em novas tecnologias para melhorar o sistema férreo no país aumenta a cada ano, priorizando a acessibilidade, eficiência energética, baixa poluição e segurança.

Quando observados os registros avaliados nesta pesquisa por seus respectivos inventores, o chinês Chen Guangwu (03) e os japoneses Asano Akira (02) e Kobayashi Hiroyuki (02) lideram o número de patentes relacionadas ao tema, confirmando os orientais como principais criadores destes produtos e/ou serviços. Outros inventores chineses e japoneses aparecem na lista, tendo, cada um deles, apresentado um registro/patente relacionado a este estudo, conforme a Figura 7.

Figura 7 - Registros de patentes por inventores

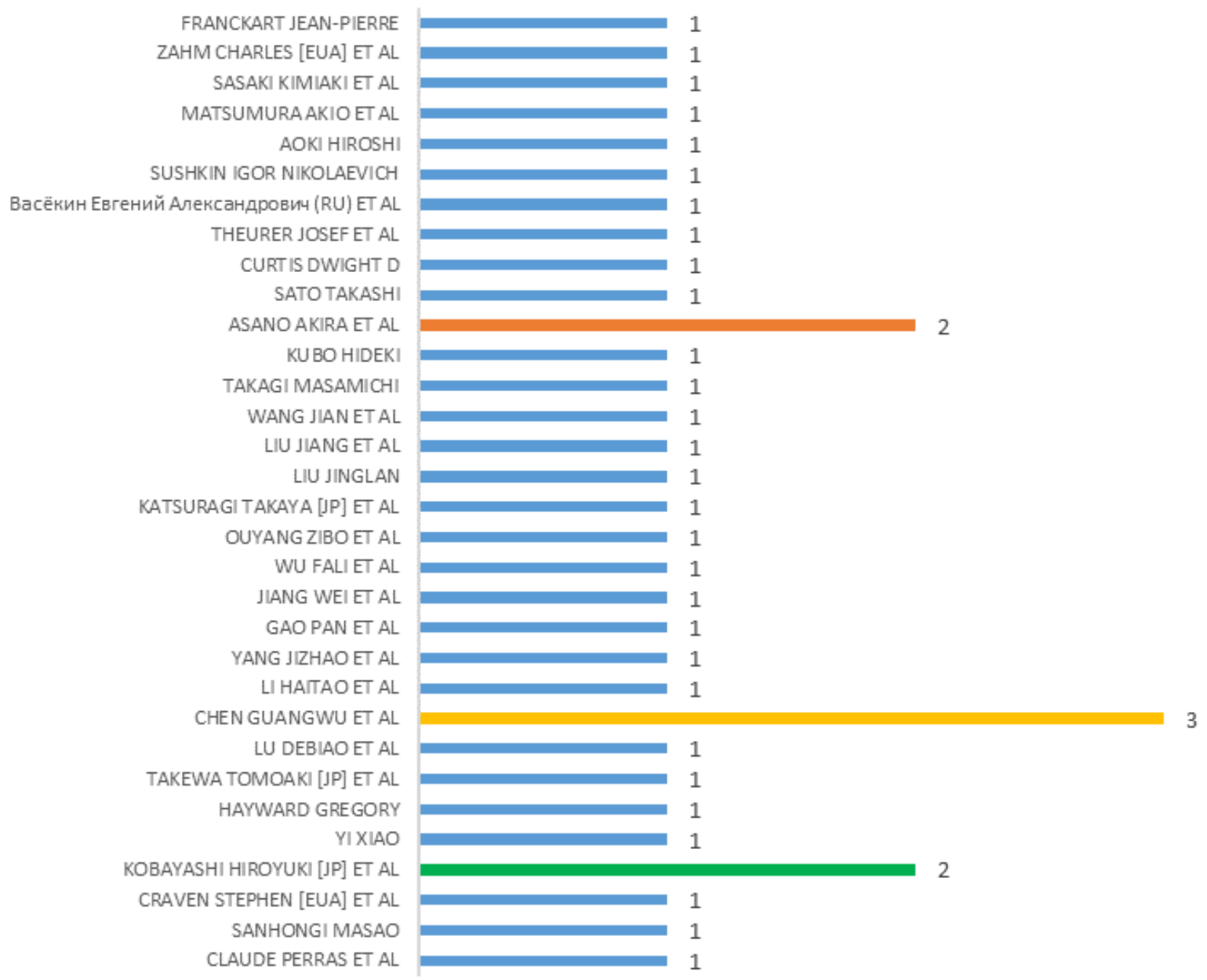

Fonte: Elaborada pela autora deste artigo (2019) 


\section{Considerações Finais}

O pouco investimento em tecnologia voltada para serviços aos usuários de trem ferroviário e metroferroviário é uma realidade na maioria das operadoras destes sistemas no Brasil. $\mathrm{O}$ presente estudo mostra que os registros de patentes relacionadas a este tema, sobretudo na plataforma do INPI, são praticamente inexistentes, reforçando a importância de desenvolver projetos e pesquisas que atendam a uma demanda reprimida junto aos passageiros atendidos por estes dois modais de transporte.

Apenas em São Paulo estão disponíveis dois aplicativos que oferecem serviços em tempo real voltados para o metrô paulistano com horários, mapas e outras funcionalidades que podem ser acessadas pelos seus usuários. No entanto, como já apresentado neste estudo, os dois dispositivos têm pontos de melhoria que precisam ser levados em conta, sobretudo para ampliar o relacionamento e o atendimento ao público.

A mobilidade de pessoas, seja no uso diário do transporte seja ao cruzar a linha férrea, influencia diretamente na boa relação da sociedade com as empresas (públicas ou privadas), além de promover qualidade de vida aos habitantes das cidades por onde passam os trens com serviços que facilitam a rotina de tráfego urbano.

Desta forma, é latente a necessidade de garantir serviços de qualidade e que assegurem a mobilidade das pessoas nos centros urbanos e outras localidades dotadas de sistemas de transporte de trens e metrôs.

Como forma de ampliar este estudo, futuramente, propõe-se uma pesquisa de avaliação junto aos usuários de trens e metrôs no Brasil que possa identificar a real necessidade destes passageiros em relação aos serviços prestados à sociedade pelas concessionárias e empresas que administram estes sistemas, hoje, no país, identificando oportunidades para o incremento tecnológico neste ramo de atuação, bem como canais de relacionamento para fortalecer a imagem e reputação destas empresas.

\section{Referências}

ASSOCIAÇÃO NACIONAL DE TRANSPORTES FERROVIÁRIOS (ANTF). Propostas da ANTF para o novo governo. Brasília, 2018. 5 p.

AGÊNCIA NACIONAL DE TRANSPORTES TERRESTRES (ANTT). Trem de Passageiros: uma necessidade que se impõe. Disponível em: https://pt.scribd.com/document/349408143/Trens-dePassageiros-Uma-Realidade-Que-Se-Impoe. Acesso em: 23 jul. 2019.

ESTUDO APONTA TRENS COMO ALTERNATIVA PARA MELHORAR MOBILIDADE NAS

GRANDES CIDADES. 2014. Disponível em: http://portal.antt.gov.br/index.php/content/view/31767/ Estudo_aponta_trens_como_alternativa_para_melhorar_mobilidade_nas_grandes_cidades_html. Acesso em: 23 jul. 2019.

BAZANI, Adamo. Projeto de Lei de concessão das linhas da CPTM e do Metrô à iniciativa privada tramita na Alesp. 2019. Disponível em: https://diariodotransporte.com.br/2019/06/20/ projeto-de-lei-de-concessao-das-linhas-da-cptm-e-do-metro-a-iniciativa-privada-tramita-na-alesp/. Acesso em: 28 jul. 2019. 
CONFEDERAÇÃO NACIONAL DO TRANSPORTE. Transporte metroferroviário de passageiros. Brasília: CNT, 2016. 149 p.

EUROPEAN PATENT OFFICE (Espacenet). Portal virtual. 2017. Disponível em: https://worldwide. espacenet.com. Acesso em: 25 jul. 2019.

EXPANSÃO FERROVIÁRIA CHINESA MOSTRA EFICIÊNCIA DO ESTADO COMO MOTOR DO DESENVOLVIMENTO. Carta Maior. 2018. Disponível em: https://www.cartamaior.com.br/?/ Editoria/Economia-Politica/Expansao-ferroviaria-chinesa-mostra-eficiencia-do-Estado-como-motordo-desenvolvimento/7/39056. Acesso em: 24 jul. 2019.

IG Tecnologia \& Games. Disponível em: https://tecnologia.ig.com.br/2014-05-21/greve-de-onibusem-sp-veja-aplicativos-que-informam-onde-estao-os-coletivos.html. Acesso em: 25 jul. 2019.

INSTITUTO DO PATRIMÔNIO HISTÓRICO E ARTÍSTICO NACIONAL. Manual Técnico do Patrimônio Ferroviário. Disponível em: http://portal.iphan.gov.br//uploads/publicacao/manual_ tecnico_patrimonio_ferroviario.pdf. Acesso em: 29 jul. 2019.

INSTITUTO DO PATRIMÔNIO HISTÓRICO E ARTÍSTICO NACIONAL (IPHAN). História das

Ferrovias no Brasil. Disponível em: http://portal.iphan.gov.br/pagina/detalhes/609. Acesso em: 29 jul. 2019.

INSTITUTO NACIONAL DA PROPRIEDADE INDUSTRIAL (INPI). Portal virtual. 2019. Disponível em: http://www.inpi.gov.br/. Acesso em: 24 jul. 2019.

MARTIN, C. Mobile Marketing: como estar em contato com seus clientes através de smartphones, tablets e outros dispositivos móveis. São Paulo: M. Books do Brasil, 2013.

MIRAGAIA, M.; CARAM, B. Ministro da Infraestrutura anuncia a concessão de três novas ferrovias. 2019. Disponível em: https://www1.folha.uol.com.br/mercado/2019/01/ministro-dainfraestrutura-anuncia-a-concessao-de-tres-novas-ferrovias.shtml. Acesso em: 28 jul. 2019.

PLAY STORE. Disponível em: https://play.google.com/store/apps/details?id=br.com.metrosp. appmetro\&showAllReviews=true. Acesso em: 25 jul. 2019.

RELATÓRIO ANUAL AMTRACK 2011. Disponível em: https://www.amtrak.com/ccurl/677/158/2011Amtrak-Annual-Report-Final.pdf. Acesso em: 13 jul. 2019.

TATTO, J. A. Mobilidade urbana em São Paulo: aplicação de soluções imediatas e eficazes. São Paulo: USP, 2015. 164 p.

THE TIMES HIGHER EDUCATION. The World University Rankings. Disponível em: https://www. timeshighereducation.com/world-university-rankings/2019/reputation-ranking\#!/page/0/length/25/ sort_by/rank/sort_order/asc/cols/stats. Acesso em: 21 jul. 2019.

Velocidade e eficiência por meio do avanço tecnológico. Embaixada do Japão no Brasil, São Paulo. Disponível em: https://www.br.emb-japan.go.jp/cultura/transporte.html. Acesso em: 21 jul. 2019. 


\section{Sobre os Autores}

\section{Adriana Monteiro da Cunha}

E-mail:montedrica@gmail.com

Especialista em Marketing Digital pela Pontifícia Universidade Católica de Minas Gerais (PUC-MG).

Endereço profissional: Rua São Miguel, n. 818. Bairro: Jurunas, Belém, PA. CEP: CEP: 66033-015. 